\title{
Radiofrequency ablation for benign thyroid nodules according to different ultrasound features: an Italian multicentre prospective study
}

\author{
Maurilio Deandrea', Francesca Garino ${ }^{1}$, Mormile Alberto ${ }^{1}$, Roberto Garberoglio², Ruth Rossettoㄹ, Nadia Bonelli², \\ Stefano Spiezia ${ }^{3}$, Massimo De Santis ${ }^{3}$, Salvatore Monti ${ }^{4}$, Maria Grazia Deiana ${ }^{4}$, Toscano Vincenzo ${ }^{4}$, \\ Christian Cugini ${ }^{5}$, Ghassan El Dalati ${ }^{6}$ and Paolo Piero Limone ${ }^{1}$ \\ Endocrinology and Metabolism ${ }^{1}$ Mauriziano Hospital Umberto I, ${ }^{2}$ Molinette Hospital, Turin, Italy, ${ }^{3}$ Endocrine Surgery, \\ Ospedale del Mare, ASL NA1 Centro, Naples, Italy, ${ }^{4}$ Endocrinology Unit, Azienda Ospedaliera Universitaria Sant'Andrea, \\ Rome, Italy, Radiology Department ${ }^{5}$ Villa Salus Hospital, Venice, Italy, and ${ }^{6}$ Policlinico G.B.Rossi, Verona, Italy

\section{Correspondence} \\ should be addressed \\ to M Deandrea \\ Email \\ mdeandrea@mauriziano.it
}

\section{Abstract}

Background: The purpose of this study was to confirm the generalisation of radiofrequency ablation (RFA) in the treatment of benign thyroid nodules (BTN) and to look for a correlation between final shrinkage and some ultrasound (US) findings in a large Italian population data set.

Methods: This prospective study included 337 patients with solid cold BTN from six Italian institutions. Nodule volume, US pattern, thyroid function, symptom/cosmetic scores and complications were evaluated before treatment and at 6 and 12 months. The primary outcome was to find a correlation between basal volume and US pattern of the nodules and final shrinkage. The secondary outcome was to confirm the efficacy and safety of RFA in a large data set. Results: The median basal volume was $20.7 \mathrm{~mL}$, and this significantly decreased after RFA at 6 months $(7.3 \mathrm{~mL}(-63.5 \%)$, $P<0.001)$ and at 12 months $(6 \mathrm{~mL}(-70 \%), P$ vs 6 months $=0.009)$. A significant correlation was found for US structure (a spongiform pattern showing a $76 \%$ reduction vs 67 and $66 \%$ of mix and solid patterns respectively, $P<0.01$ ) as well as for vascularity (intense peripheral and intranodal patterns showing 71 vs 68 and $67 \%$ of weak peripheral and intranodal and peripheral patterns respectively, $P<0.03$ ), but not for macrocalcifications. A slight inverse correlation was found between nodule basal volume and shrinkage (Spearman: -0.23 ). Mean symptoms/cosmetic scores were significantly reduced. No major complications were encountered.

Conclusions: This multicentre study validated the efficacy and safety of RFA for treating BTN and showed a clear correlation between final shrinkage and some common US findings.

\section{Introduction}

Nodular thyroid disease is a common clinical problem, the incidence of which increases with age and with the widespread use of thyroid ultrasonography $(1,2,3,4)$. Although most thyroid nodules are benign and need only periodic monitoring, some tend to grow and require treatment, due to associated pressure and/or cosmetic symptoms (5).
Surgery is the main therapeutic approach for compressive thyroid nodules, but it may be associated with several drawbacks, such as hypoparathyroidism, laryngeal palsy, haemorrhage or wound infection (6).

Long-term levothyroxine suppression treatment is ineffective in particular in the case of large nodules; 
furthermore, in elderly patients it is associated with adverse bony and cardiovascular side effects $(3,4)$. Radioiodine therapy, although inexpensive and safe, may be ineffective in large cold nodules (7). Nonsurgical, minimally invasive treatment modalities such as ethanol ablation (EA) (8), percutaneous laser ablation (LA) $(9,10$, $11,12)$ and radiofrequency ablation (RFA) (13, 14, 15, $16,17,18)$ are used to treat thyroid nodules. EA is highly effective for treating cystic nodules, but it is disappointing in solid nodules $(19,20,21)$. LA is able to reduce the nodule volume by $40-70 \%(20,21)$, and clinical outcomes in patients followed up for more than 5 years indicate that LA results in satisfactory nodule shrinkage over time in most patients (12). RFA of thyroid nodules, introduced in 2006 (15), has been reported to be both safe and effective; BTNs have shown $50-80 \%$ shrinkage $(20,21,22)$ with new devices and treatment modalities adopted over the last decade (23).

Recent international guidelines recommend miniinvasive techniques for treating selected BTN (4). However, the ultrasound (US)features predictive of the outcome of thermoablative treatments are still not well understood, and the studies published so far have provided only partial information regarding this important issue (24).

The main purpose of this multicentre study was to assess the efficacy and safety of RFA in the treatment of BTN in different Italian groups sharing the same criteria for nodule selection, technology and treatment methodology.

A further aim was to detect a possible relationship between baseline nodule characteristics, including volume and common sonographic features, and the extent of the shrinkage.

\section{Subjects and methods}

Six different Italian institutions participated in this prospective study. All of whom shared the same training programme with an experience of at least 50 RFA procedures and accepted to use the same unified protocol and similar devices.

The study was approved by the Institutional Review Board of the six participating centres (Mauriziano Hospital Turin, Molinette Hospital Turin, Ospedale del Mare Naples, Sant'Andrea Hospital Rome, Policlinico Hospital Verona and Villa Salus Hospital Venice), and patient consent was obtained in all cases.

Inclusion criteria were patients aged 18 years or older, no previous external beam radiation or $\mathrm{I}^{131}$ treatments, cosmetic or compressive symptoms in patients with refusal or ineligibility for surgery.

The nodules were mostly solid (with a cystic portion of less than $30 \%$ ), cold at $99 \mathrm{mTc}$ pertechnetate scintigraphy, with a volume larger than $5 \mathrm{~mL}$ or with a minimum diameter greater than $1 \mathrm{~cm}$. The Bethesda reporting system was used for cytological classification: patients with Bethesda Class II findings were enrolled (25). Benignity was confirmed by two repeated fine-needle aspirations (THY 2). Exclusion criteria were pregnancy, malignant (THY 5) or suspicious (THY 3-THY 4) thyroid nodules, nodules with a volume smaller than $5 \mathrm{~mL}$ or with a minimum diameter of $10 \mathrm{~mm}$ or nodules that were confluent with others in a lobar mass.

In patients with multiple nodules, the largest and/or the most symptomatic one was treated, and every nodule underwent only one treatment session.

In all patients, clinical, biochemical and US evaluation were carried out at baseline and at 6 and 12 months after RFA.

\section{Clinical evaluation}

We classified symptoms and cosmetic scores as described in a previous consensus statement (26). All patients were asked to rate pressure symptoms on a $10 \mathrm{~cm}$ visual analogue scale (grade $0-10 \mathrm{~cm}$ ) at enrolment and at follow-up visits. A cosmetic score was obtained according to a clinical scale .

\section{Biochemical evaluation}

Serum TSH, FT4, antithyroid peroxidase and antithyroglobulin antibodies were determined with commercially available immunometric kits. Coagulation tests, including INR and platelet count, were performed.

\section{Ultrasound evaluation}

All the interpreting physicians operating in the centres involved in this study performed US and US-guided FNA by using commercially available US scanner, equipped with $7.5-13 \mathrm{MHz}$ linear probe.

On US examination, carried out before the treatment, three orthogonal diameters (the largest diameter and two other mutually perpendicular diameters) of each nodule were measured, and the volume of the nodules was calculated with the following equation: $V=0.524 \cdot a b c$ (where $V$ is volume, $a$ is the largest diameter and $b$ 


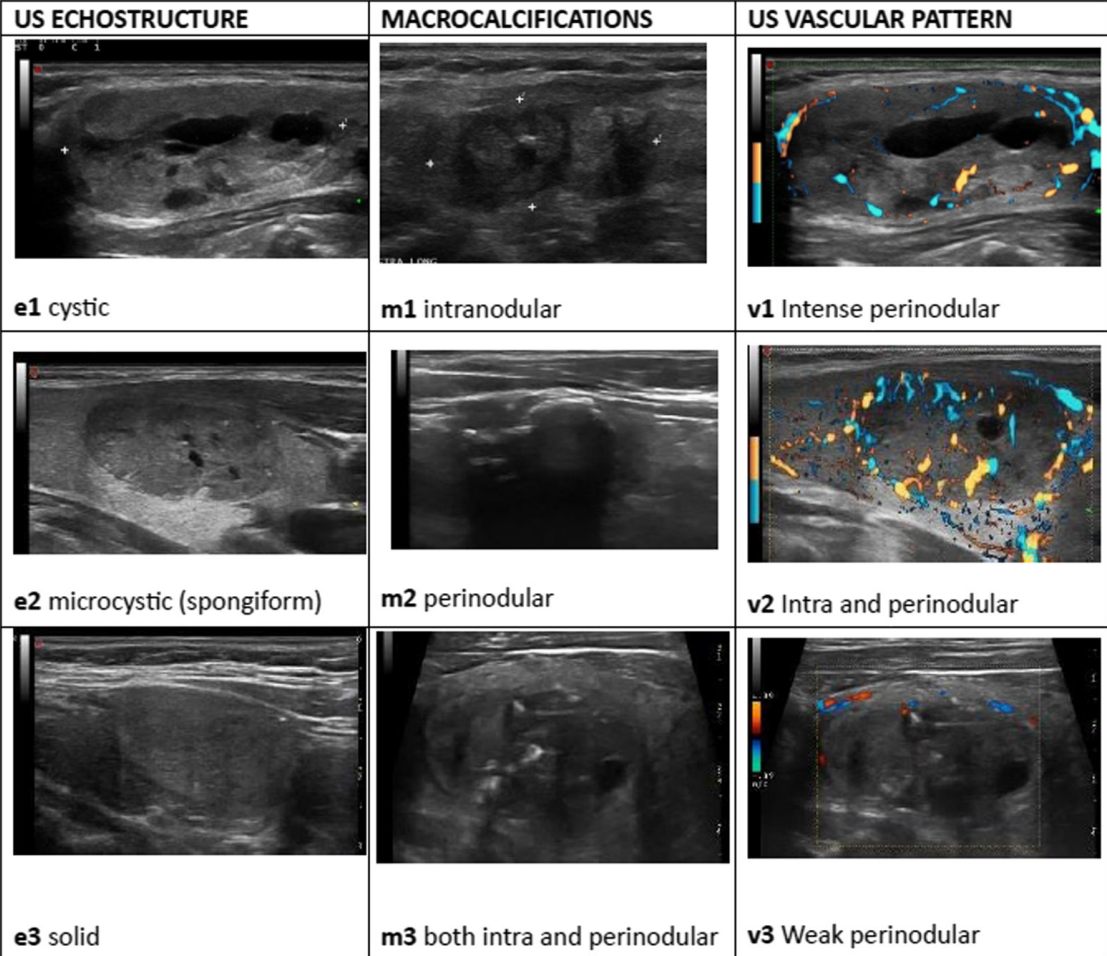

\section{Figure 1}

Echostructure was scored as cystic (e1) when few medium-sized areas are present, microcystic (e2) when many little cystic areas $<2 \mathrm{~mm}$ give a 'spongiform' appearance, solid (e3) when no cystic areas are detectable. Macrocalcifications, when present, may be only intranodular $(\mathrm{m} 1)$, only perinodular eventually with 'egg shell' appearance $(\mathrm{m} 2)$, both peripheral and intranodular (m3). Vascularisation can be intense perinodular (v1), peri- and intranodular (v2) or weak and just detectable around the nodule (v3). and $c$ are the other two perpendicular diameters) (14). Furthermore, every nodule received a score concerning US structure, US vascular pattern and the presence or the absence of macrocalcifications (classified to the type, if present), according to a reference Atlas agreed (Fig. 1). US vascular pattern recorded in the participating centres was available for 225 out of 337 nodules.

\section{RFA procedures}

In different centres, the RFA procedures were performed in three centres by endocrinologists with an experience of 6-10 years, in one centre by an endocrine surgeon with an experience of 10 years and in the remaining two centres by two interventional radiologists with 3 and 5 years of experience using the 'moving shot technique' (14). The treating physicians were different from the interpreting physicians.

All procedures were performed under US guidance on an outpatient basis. A single session of RFA was performed with the patient in a supine position and with mild neck extension, without any sedation. The radiofrequency device used was a cool-tip RF system with a straight type modified internally cooled electrode, all of the same size $(18 \mathrm{G})$, length $(7 \mathrm{~cm})$ and with a $10 \mathrm{~mm}$ active part of the needle (RF Medical Seoul Korea or STARMed Co Seoul Korea).
In order to prevent serious haemorrhage, vessels located along the approach route were carefully evaluated by using Doppler US. The puncture site was anaesthetised with $2 \%$ lidocaine or $1 \%$ mepivacain. The skin was punctured by using the trans-isthmic approach method, in which the electrode is inserted through the short axis of the target nodule from the isthmus; the energy setting and the criteria to optimise its use are described by Baek et al. $(14,16)$. The goal of the treatment is to reach, as much as possible, every part of the nodule, in order to change the echostructure towards a hypoechogenic pattern, with the help of the generator which shuts down power when coagulation is obtained and impedance increases (Fig. 2). The applied power and the actual time of treatment were recorded at the end of each session. At the end of the procedure, an ice pack was applied to the patient's neck with mild compression, and the patient underwent observation for about $2 \mathrm{~h}$.

\section{Follow-up}

The outcomes were assessed by two experienced sonographers in each centre who were different from the operators. US examination was performed in order to measure the nodule volume and to score the US structure according to the reference Atlas (Fig. 1) and to record 


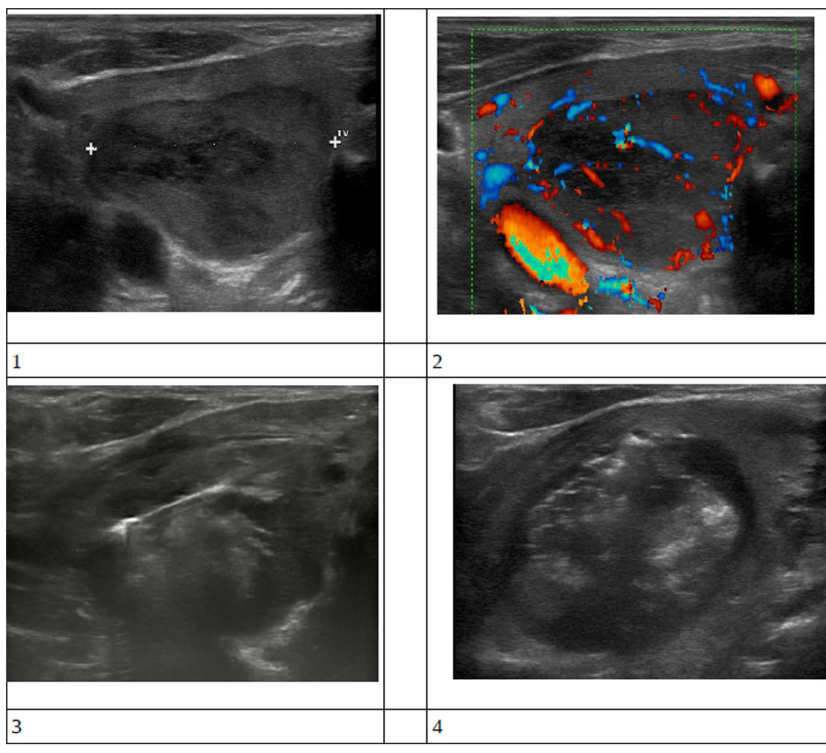

Figure 2

Treatment procedure: (1) US evaluation before treatment; (2) US vascular pattern before treatment; (3) hyperechoic spot during treatment; (4) final US pattern at the end of procedure. A full colour version of this figure is available at https://doi. org/10.1530/EJE-18-0685.

compressive and cosmetic scores in all subjects, at 6 and 12 months after treatment.

\section{Study end points}

The primary end point was the quantitative volume reduction ratio of TNs and the improvement in pressure symptoms and in cosmetic discomfort.

The secondary end point was to determine whether there was a relationship between baseline nodule volume and sonographic features and the extent of the shrinkage in a large multicentre study.

Major and minor complications were assessed according to the recommendations of the Society of Interventional Radiology (26).

\section{Statistical analysis}

Continuous variables describing patients and nodules are expressed as median with interquartile range, as nonparametric.

Statistical differences in continuous variables were assessed by the Wilcoxon test for paired samples, and by the ANOVA test when comparing multiple groups.
Correlations between variables were verified by the Spearman test and expressed with 95\% Fisher CI. Categorical variables (scores) were compared by the Pearson $\chi^{2}$ test.

Two-sided $P$ values of $<0.05$ were considered statistically significant. Analysis was performed using Analyse-it TM Software v 4.60.1 (Leeds, UK).

\section{Results}

Clinical, demographic and laboratory findings of the studied population and treatment characteristics of enrolled patients who completed the follow-up at 12 months are reported in Table 1.

From January 2014 to December 2016, 337 patients with proven BTN were included in this study, treated and followed for 12 months.

The median basal nodule volume was $20.7 \mathrm{~mL}$ and significantly decreased 6 months after treatment to $7.3 \mathrm{~mL}$ (-63.5\%, $P<0.001)$; a further significant shrinkage to $6 \mathrm{~mL}$ occurred at 12 months $(-70 \%$ vs baseline, $P<0.001$; $P=0.009$ vs 6 months) (Fig. 3). The volume reduction rate ranged from 65 to $85 \%$ and the curve of reduction during follow-up was similar in different participating centres (Fig. 4). Regarding thyroid function, TSH was not altered at 12 months follow-up (median 1.2 vs $1.8 \mathrm{mIU} / \mathrm{L}$ post RFA, CI $0.5-2$ vs $0.8-2.35, P$ ns) and AbTPO-positive patients were not increased after RFA (74 pts + after treatment, 24 vs $22 \%$ post RFA of the entire group, $P$ ns).

In order to more accurately assess the relationship between volume reduction and baseline volume, the nodules were further divided into three groups: group A, with a volume less than $15 \mathrm{~mL}$ (103 nodules), group B,

Table 1 Baseline clinical and treatment data.

\begin{tabular}{|c|c|c|}
\hline Parameters & Values & $\begin{array}{c}\text { Confidence } \\
\text { interval }\end{array}$ \\
\hline Number of patients & 337 & \\
\hline Female & $76 \%$ & \\
\hline Age & 55 years & $40-73$ \\
\hline $\mathrm{TSH}$ & $1.2 \mathrm{mIU} / \mathrm{L}$ & $0.5-2$ \\
\hline FT4 & 10 (pg/mL) & $8-13$ \\
\hline AbTPO positive & $24 \%$ & \\
\hline Compressive score $(0-10)$ & 6.2 (median) & \\
\hline Aesthetic score (1-4) & 3.15 (median) & \\
\hline Baseline volume & $20.7 \mathrm{~mL}$ & $13.7-33.1$ \\
\hline \multicolumn{3}{|l|}{ Energy } \\
\hline Power & $55 w$ & $50-62$ \\
\hline Time & $10 \mathrm{~min}$ & $7-15$ \\
\hline Delivered/volume & $2180 \mathrm{~J} / \mathrm{mL}$ & $1350-2847$ \\
\hline
\end{tabular}




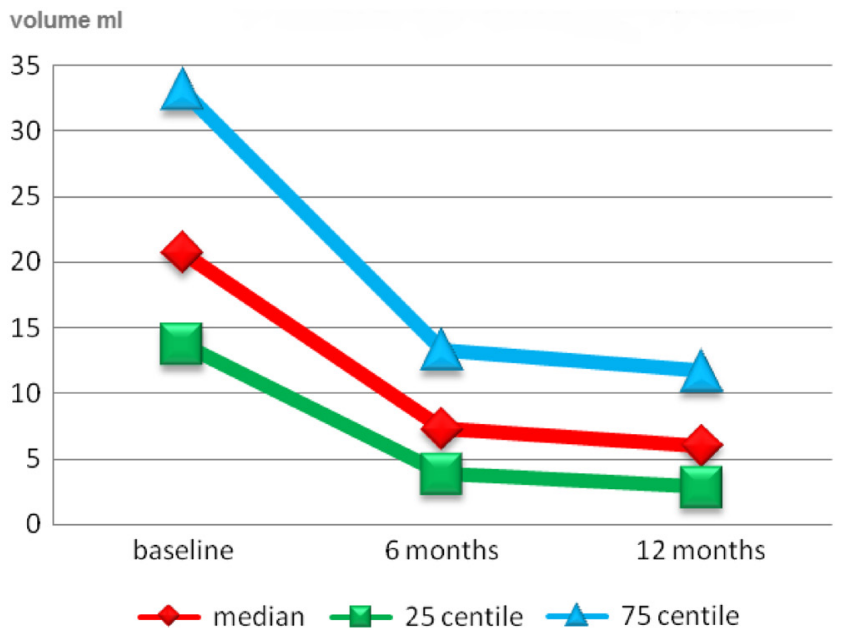

Figure 3

Nodules' volume shrinkage by time after RFA. A full colour version of this figure is available at https://doi.org/10.1530/ EJE-18-0685.

with a volume between 15 and $30 \mathrm{~mL}$ (129 nodules) and group C, with a volume larger than $30 \mathrm{~mL}$ (105 nodules). A significant difference in nodule shrinkage was found at 12 months $(P<0.001)$ with a greater reduction for group A (-76.7\% vs baseline) than that for B and C (-67.3 and $66.7 \%$ respectively) (Table 2 ). The distribution of nodule reduction in different centiles evidenced that the vast majority had a reduction between 50 and $90 \%$ from basal volume (Fig. 5).

As regards the energy delivered to the nodular tissue $(2180 \mathrm{~J} / \mathrm{mL})$, no correlation was found between the amount of delivered energy and the volume reduction (Rs 0.09 ; $95 \%$ CI -0.02 to 0.19 ) in the whole nodule group; however, if we consider the energy delivered in the three groups of nodules, the smaller nodules received an amount of energy/mL which was significantly higher than that for larger nodules $(2940 \mathrm{~J} / \mathrm{mL}$ in group $\mathrm{A}, 2220 \mathrm{~J} / \mathrm{mL}$ in group $\mathrm{B}$ and $1200 \mathrm{~J} / \mathrm{mL}$ in group $\mathrm{C}, P<0.001)$. No difference in US structure (see the US characteristics reported in the Atlas, Fig. 1) was recorded at multivariate analysis in the three volume groups.

Microcystic (spongiform) nodules showed a significantly better outcome than scarcely microcystic and solid nodules at 6 months (68\% reduction vs $64 \%$ and $60 \%$ respectively, $P=0.04)$ and 12 -month follow-up $(76 \%$ reduction vs $68 \%$ and $68 \%$ respectively, $P$ 0.01) (Table 2 ).

Type 2 US vascular pattern (intra- and perinodular) resulted in a more favourable outcome than both intense and weak perinodular patterns at 6 months
(62\% reduction vs 56\% and 50\% respectively, $P<0.01$ ) and at 1 -year follow-up (71\% vs $68.8 \%$ and $67.9 \%$ respectively, $P<0.03$ ) (Table 2).

The presence of coarse calcifications did not influence the RFA outcome at 6 or 12 months $(P 0.68$ and 0.94 respectively); no difference was found in nodule's reduction after RFA comparing AbTPO+ and AbTPOgroups ( $P$ 0.97).

Both compressive and aesthetic scores significantly improved at 1 -year follow-up ( $P<0.0001$ for both); details are summarised in Table 3.

A total of 238 patients (71.6\%) experienced no complications at all, 45 (13\%) complained of minimal side effects, 52 (15\%) had minor complications and 2 (0.4\%) experienced major complications, listed in Table 4 with their severity degree. All patients had a complete recovery without any permanent side effects.

\section{Discussion}

Most BTN are asymptomatic and remain fairly stable over time; however, a significant number show a slow but progressive growth (5), causing patient concern, and requiring repeated medical consultations, US examinations and, frequently, thyroid surgery.

Many scientific association guidelines (33, 34, 35) consider US-guided thermal ablation an effective

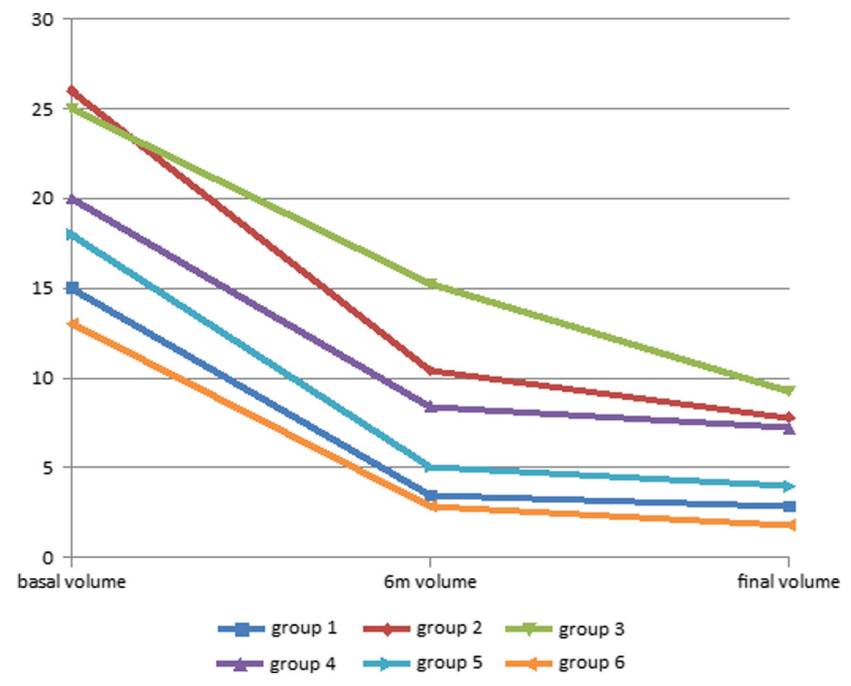

Figure 4

Nodule volume reduction in six different centres participating the study. A full colour version of this figure is available at https://doi.org/10.1530/EJE-18-0685. 
Table 2 Factors affecting outcomes of 337 benign thyroid nodules after RFA.

\begin{tabular}{|c|c|c|c|c|c|}
\hline & \multirow[b]{2}{*}{ Delivered energy $(\mathrm{J} / \mathrm{mL})$} & \multicolumn{3}{|c|}{ Volume before (median) $(\mathrm{mL})$} & \multirow[b]{2}{*}{$\boldsymbol{P}$} \\
\hline & & Before & 6 months & 12 months & \\
\hline Whole group (337 nodules) & 2180 & 20.7 & $7.3(-63.5 \%)$ & $6(-70)$ & $<0.001$ \\
\hline Volume $<15$ mL (103 nodules) & 2940 & 11.2 & 3.2 & $2.5(-76.7)^{* *}$ & $<0.001 * *$ \\
\hline Volume $15-30 \mathrm{~mL}$ (129 nodules) & 2200 & 20.7 & 7.5 & $6.5(-67.3)$ & \\
\hline Volume $>30 \mathrm{~mL}$ (105 nodules) & 1200 & 41 & 16.6 & $15(-66.7)$ & \\
\hline \multicolumn{6}{|l|}{ US pattern } \\
\hline E1 & & 21 & 7.5 & $6.6(-69)$ & \\
\hline E2 & & 19.9 & 6.2 & $4.9(-76)$ & $0.01 * *$ \\
\hline E3 & & 22.1 & 8 & $6.9(-68)$ & \\
\hline \multicolumn{6}{|l|}{ Vascularity pattern } \\
\hline V1 & & 21.9 & 7.9 & $7.2(-68.8)$ & \\
\hline V2 & & 18.9 & 6.2 & $5.5(-71)$ & $<0.03 * *$ \\
\hline V3 & & 20.1 & 8.7 & $6.5(-67.9)$ & \\
\hline \multicolumn{6}{|l|}{ Macrocalcifications } \\
\hline M1 & & 23 & 8.5 & $6.5(-71.5)$ & NS** \\
\hline M2 & & 20 & 6.9 & $6(-70)$ & \\
\hline M3 & & 24.8 & 9.5 & $8.2(-69.8)$ & \\
\hline
\end{tabular}

treatment for those nodules which are becoming clinically symptomatic.

Our current prospective multicentre study, involving trained endocrinologists and radiologists using similar techniques and devices, confirmed the efficacy and safety of RF ablation in a large cohort of patients.

As to the primary outcome, the mean volume reduction was about $70 \%$ at 1-year follow-up (with a range between 65 and $85 \%$ in different centres in Italy), followed by a significant improvement in compressive symptoms and aesthetic discomfort; the volume reduction is comparable to that reported in previous studies $(14,16$, 22 ) and confirmed in a recent review (27), no recurrences were recorded in our series. As previously described, we excluded very small nodules, in order to avoid thermal damage beyond the nodule capsule $(24,27,28)$.

Interestingly, in this series of 337 nodules we observed a trend towards an inverse correlation between basal nodule volume and final volume shrinkage, in particular when considering nodules with a volume $<15 \mathrm{~mL}$. Our results demonstrate that the treatment may give similar results in nodules up to a maximum diameter of $3-4 \mathrm{~cm}$, while it may be less effective in larger nodules. This data is in agreement with a previous observation by Spiezia et al. (16), and partially confirms the observation by Pacella et al. (31): however, it is worth noting that in the latter survey the data came from different groups not using the same RFA treatment protocol.

On the whole, most reports agree that nodules larger than $5 \mathrm{~cm}$ shrink less than smaller nodules, probably owing to retrosternal extension of the nodules which prevents a complete treatment with the trans-isthmic approach; a further explanation could be that larger nodules received less energy than smaller nodules, as suggested by our findings, and may show a marginal regrowth at a longer follow-up (25). Such observation would prompt us to modify the treatment strategy when we treat very large

Table 3 Compressive and cosmetic score before and at 12 months after RFA.

\begin{tabular}{|c|c|c|}
\hline & \multicolumn{2}{|c|}{ No. of patients } \\
\hline & Before & 12 months \\
\hline \multicolumn{3}{|c|}{ Visual scale: Compressive score } \\
\hline 0 & 66 & 248 \\
\hline 1 & 2 & 18 \\
\hline 2 & 16 & 46 \\
\hline 3 & 41 & 9 \\
\hline 4 & 34 & 9 \\
\hline 5 & 57 & 7 \\
\hline 6 & 41 & 0 \\
\hline 7 & 34 & 0 \\
\hline 8 & 36 & 0 \\
\hline 9 & 9 & 0 \\
\hline 10 & 2 & 0 \\
\hline Median & 6.2 & 0.61 \\
\hline \multicolumn{3}{|c|}{ Clinical evaluation: Cosmetic score } \\
\hline 1 & 1 & 147 \\
\hline 2 & 83 & 158 \\
\hline 3 & 115 & 30 \\
\hline 4 & 138 & 2 \\
\hline Median & 3.15 & 1.66 \\
\hline $\begin{array}{l}\text { Compressive } \\
\text { classified on } \\
\text { but palpable } \\
\text { visible mass. }\end{array}$ & $\begin{array}{l}\text { th a vis } \\
\text { alpable } \\
\text { oblem }\end{array}$ & $\begin{array}{l}\text { nic score was } \\
\text { netic problem } \\
\text { ig; 4: easily }\end{array}$ \\
\hline
\end{tabular}


Table 4 Side effects and complications.

\begin{tabular}{ll}
\hline Degree & Type \\
\hline Major & $\begin{array}{l}\text { Voice change } \\
\text { Nodule infection } \\
\text { Minor }\end{array}$ \\
& $\begin{array}{l}\text { Oedema } \\
\text { Superficial ematoma } \\
\text { Suscle ematoma }\end{array}$ \\
Side effects & $\begin{array}{l}\text { Pain } \\
\text { Cough }\end{array}$ \\
& Fever \\
Permanent & Complications \\
\hline
\end{tabular}

\begin{tabular}{c} 
Number \\
\hline 1 \\
1 \\
20 \\
25 \\
7 \\
42 \\
1 \\
2
\end{tabular}

\begin{tabular}{llc}
\hline Recovery time (day) & & $\%$ \\
\hline $3-7$ & & 0.4 \\
30 & & 15 \\
0.2 & \\
7 & \\
14 & 13 \\
$\begin{array}{l}\text { Intraoperatively } \\
\text { Intraoperatively }\end{array}$ & \\
1 day & - \\
\hline
\end{tabular}

nodules with an additional treatment session and delivery of more energy per volume unit.

On the contrary, the results of the present study confirm that in compressive thyroid nodules with a volume of less than $15 \mathrm{~mL}$, a second treatment session is unnecessary in most cases, as was previously reported by the Korean authors (28).

Another issue of the present study, and perhaps the most important, is that we were able to identify some US features of the nodules that can be predictive of the final outcome.

As a matter of fact, microcystic nodules (also called spongiform) and the grossly cystic ones shrank better than the nodules with a homogeneous solid US pattern: although a similar finding was previously reported by Valcavi et al. (12) and by Negro et al. (29) in nodules treated by laser, to our knowledge this is the first clear demonstration of a correlation between spongiform structure and volume reduction in RF-treated nodules.

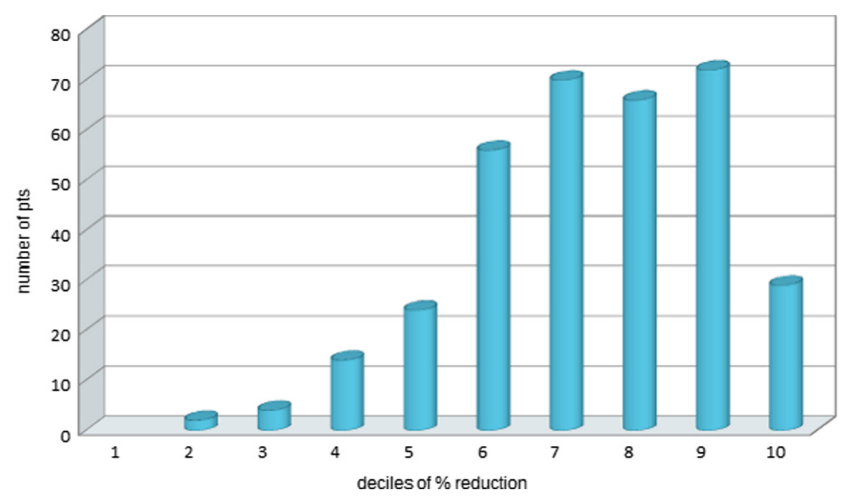

\section{Figure 5}

Distribution of the entire nodules' group in different Deciles of Percentage Reduction: (1) <10\%; (2) 11-20\%; (3) 21-30\%; (4) 31-40\%; (5) 41-50\%; (6) 51-60\%; (7) 61-70\%; (8) 71-80\%; (9) $81-90 \%$; (10) $91-100 \%$. A full colour version of this figure is available at https://doi.org/10.1530/EJE-18-0685.
As to the predictive value of the pattern of vascularisation, literature data reported conflicting results; we showed that the intense peripheral or peripheral and intranodular vascularisation can predict a better response to treatment. The possible explanation of our observation is that heating produces more steam in the case of tissue with a large fluid component, colloid or blood and that the steam enhances the thermocoagulative process in the treated nodule. This mechanism may be shared by all thermoablative techniques, whatever the heating source: LA, RFA, HIFU, microwaves and so on.

In our series, the coarse calcifications do not appear to have a negative impact on shrinkage if they are not too large to impair the needle insertion or tracking during treatment; this is surprising, since it is common opinion that gross calcifications could impair the diffusion of the heat and disturb the movement of the electrode tip, thus reducing the efficacy of thermoablative treatment.

Serum levels of TSH and FT4 showed no significant change 12 months after RFA. This data confirms previous reports from randomised controlled trials with LA and RFA, showing that thyroid function is not affected in patients treated with mini-invasive techniques $(11,13,22)$.

The low rate of major complications in the present series is due to the use of the trans-isthmic approach described by Baek et al. $(14,16)$. Our data confirms that this procedure prevents major and minor side effects, as already reported in a large series of patients treated with LA (30). Both efficacy and the low rate of complications are strongly supported by the recent paper published by the Korean Thyroid Radiologists Group (36).

In conclusion, the results provided by this large prospective multicentre study confirm that RFA is a clinically effective, well tolerated and safe minimally invasive technology for the nonsurgical management of symptomatic BTN. A single RFA session induces a remarkable volume reduction (about 70\%) in large solid 
nodules, without affecting thyroid function $(18,35)$ in six different centres applying the same treatment protocol.

However, the most important issue of our study is that it allowed us to identify some US features which are predictive of the outcome of the treatment; indeed, a nodule with a spongiform structure and an intense intranodular and peripheral vascularity will more likely shrink after RFA, while the presence of spot coarse calcifications should not represent a concern about RF thermal ablation. As to the nodule volume, larger nodules showed a less satisfactory response, most probably due to the lower energy delivered during the treatment.

On the whole, these observations may be important as guidance in order to select which nodules to submit to RFA and the modalities to carry out the procedure in order to obtain the best results.

\section{Declaration of interest}

The authors declare that there is no conflict of interest that could be perceived as prejudicing the impartiality of this study.

\section{Funding}

This research did not receive any specific grant from any funding agency in the public, commercial or non-profit sector.

\section{Author contribution statement}

Deandrea Maurilio: Operator and author of the paper. Mormile Alberto, Garberoglio Roberto, Spiezia Stefano, Monti Salvatore, Cugini Christian, El Dalati Ghassan: Operators. Garino Francesca, Rossetto Ruth, Bonelli Nadia, De Santis Massimo, Deiana Maria Grazia, Vincenzo Toscano, Limone Paolo Piero expert sonographers and visiting clinicians.

\section{References}

1 Gharib H \& Papini E. Thyroid nodules: clinical importance, assessment, and treatment. Endocrinology and Metabolism Clinics of North America 200736 707-735, vi. Review. (https://doi. org/10.1016/j.ecl.2007.04.009)

2 Hegedus L. Thyroid ultrasonography as a screening tool for thyroid disease. Thyroid 200414 879-880. (https://doi.org/10.1089/ thy.2004.14.879)

3 Cooper DS, Doherty GM, Haugen BR, Kloos RT, Lee SL, Mandel SJ, Mazzaferri EL, McIver B, Pacini F, Schlumberger M et al. Revised American Thyroid Association management guidelines for patients with thyroid nodules and differentiated thyroid cancer. Thyroid 2009 19 1167-1214. (https://doi.org/10.1089/thy.2009.0110)

4 Gharib H, Papini E, Paschke R, Duick DS, Valcavi R, Hegedüs L \& Vitti P. American Association of Clinical Endocrinologists, Associazione Medici Endocrinologi, and European Thyroid Association medical guidelines for clinical practice for the diagnosis and management of thyroid nodules: executive summary of recommendations. Journal of Endocrinological Investigation 201033 51-56.

5 Durante C, Costante G, Lucisano G, Bruno R, Meringolo D, Paciaroni A, Puxeddu E, Torlontano M, Tumino S, Attard M et al. The natural history of benign thyroid nodules. JAMA 2015313 926-935. (https://doi.org/10.1001/jama.2015.0956)

6 Rosato L, Avenia N, Bernante P, De Palma M, Gulino G, Nasi PG \& Pelizzo MR. Complications of thyroid surgery: analysis of a multicentric study on 14934 patients operated on in Italy over 5 years. World Journal of Surgery 200428 271-276. (https://doi. org/10.1007/s00268-003-6903-1)

7 Fast S, Nielsen VE, Bonnema SJ \& Hegedus L. Time to reconsider nonsurgical therapy of benign non-toxic multinodular goitre: focus on recombinant human TSH augmented radioiodine therapy. European Journal of Endocrinology 2009160 517-528. (https://doi. org/10.1530/EJE-08-0779)

8 Bennedbaek FN, Nielsen LK \& Hegedus L. Effect of percutaneous ethanol injection therapy versus suppressive doses of L-thyroxine on benign solitary solid cold thyroid nodules: a randomized trial. Journal of Clinical Endocrinology and Metabolism 199883 830-835. (https:// doi.org/10.1210/jcem.83.3.4673)

9 Pacella CM, Bizzarri G, Spiezia S, Bianchini A, Guglielmi R, Crescenzi A, Pacella S, Toscano V \& Papini E. Thyroid tissue: US-guided percutaneous laser thermal ablation. Radiology 2004232 272-280. (https://doi.org/10.1148/radiol.2321021368)

10 Dossing H, Bennedbaek FN \& Hegedus L. Effect of ultrasound guided interstitial laser photocoagulation on benign solitary solid cold thyroid nodules - a randomized study. European Journal of Endocrinology 2005152 341-345. (https://doi.org/10.1530/ eje.1.01865)

11 Papini E, Guglielmi R, Bizzarri G, Graziano F, Bianchini A, Brufani C, Pacella S, Valle D \& Pacella CM. Treatment of benign cold thyroid nodules: a randomized clinical trial of percutaneous laser ablation versus levothyroxine therapy or follow-up. Thyroid 200717 229-235. (https://doi.org/10.1089/thy.2006.0204)

12 Valcavi R, Riganti F, Bertani A, Formisano D \& Pacella CM Percutaneous laser ablation of cold benign thyroid nodules: a 3-year follow-up study in 122 patients. Thyroid 201020 1253-1261. (https://doi.org/10.1089/thy.2010.0189)

13 Deandrea M, Limone P, Basso E, Mormile A, Ragazzoni F, Gamarra E, Spiezia S, Faggiano A, Colao A, Molinari F et al. US-guided percutaneous radiofrequency thermal ablation for the treatment of solid benign hyperfunctioning or compressive thyroid nodules. Ultrasound in Medicine and Biology 200834 784-791. (https://doi. org/10.1016/j.ultrasmedbio.2007.10.018)

14 Jeong WK, Baek JH, Rhim H, Kim JS, Kwak MS, Jeong HJ \& Lee D. Radiofrequency ablation of benign thyroid nodules: safety and imaging follow-up in 236 patients. European Radiology 200818 1244-1250. (https://doi.org/10.1007/s00330-008-0880-6)

15 Spiezia S, Garberoglio R, Milone F, Ramundo V, Caiazzo C, Assanti AP, Deandrea M, Limone PP, Macchia PE, Lombardi G et al. Thyroid nodules and related symptoms are stably controlled two years after radiofrequency thermal ablation. Thyroid 200919 219-225. (https:// doi.org/10.1089/thy.2008.0202)

16 Baek JH, Kim YS, Lee D, Huh JY \& Lee JH. Benign predominantly solid thyroid nodules: prospective study of efficacy of sonographically guided radiofrequency ablation versus control condition. American Journal of Roentgenology 2010194 1137-1142. (https://doi.org/10.2214/AJR.09.3372)

17 Faggiano A, Ramundo V, Assanti AP, Fonderico F, Macchia PE, Misso C, Marciello F, Marotta V, Del Prete M, Papini E et al. Thyroid nodules treated with percutaneous radiofrequency thermal ablation: a comparative study. Journal of Clinical Endocrinology and Metabolism 201297 4439-4445. (https://doi.org/10.1210/jc.2012-2251)

18 Lim HK, Lee JH, Ha EJ, Sung JY, Kim JK \& Baek JH. Radiofrequency ablation of benign non-functioning thyroid nodules: 4-year follow-up results for 111 patients. European Radiology 201323 1044-1049. (https://doi.org/10.1007/s00330-012-2671-3)

19 Paschke R, Hegedus L, Alexander E, Valcavi R, Papini E \& Gharib H. Thyroid nodule guidelines: agreement, disagreement and need 
for future research. Nature Reviews Endocrinology 20117 354-361. (https://doi.org/10.1038/nrendo.2011.1)

20 Gharib H, Hegedus L, Pacella CM, Baek JH \& Papini E. Clinical review: nonsurgical, image-guided, minimally invasive therapy for thyroid nodules. Journal of Clinical Endocrinology and Metabolism 2013 98 3949-3957. (https://doi.org/10.1210/jc.2013-1806)

21 Papini E, Pacella CM \& Hegedus L. Diagnosis of endocrine disease: thyroid ultrasound (US) and US-assisted procedures: from the shadows into an array of applications. European Journal of Endocrinology 2014 170 R133-R146. (https://doi.org/10.1530/EJE-13-0917)

22 Deandrea M, Sung JY, Limone P, Mormile A, Garino F, Ragazzoni F, Kim KS, Lee D \& Baek JH. Efficacy and safety of radiofrequency ablation versus observation for nonfunctioning benign thyroid nodules: a randomized controlled international collaborative trial. Thyroid 201525 890-896 (https://doi.org/10.1089/thy.2015.0133)

23 Park HS, Baek JH, Park AW, Chung SR, Choi YJ \& LEE JH. Thyroid radiofrequency ablation updates on innovative devices and techniques. Korean Journal of Radiology 201718 615-623. (https://doi. org/10.3348/kjr.2017.18.4.615)

24 Baek JH. Factors related to the efficacy of radiofrequency ablation for benign thyroid nodules. Ultrasonography 201736 385-386. (https:// doi.org/10.14366/usg.17034)

25 Cibas ES \& Ali SZ. The Bethesda system for reporting thyroid cytopathology. American Journal of Clinical Pathology 2009132 658-665. (https://doi.org/10.1309/AJCPPHLWMI3JV4LA)

26 Burke DR, Lewis CA, Cardella JF, Citron SJ, Drooz AT, Haskal ZJ, Husted JW, McCowan TC, Van Moore A, Oglevie SB et al. Quality improvement guidelines for percutaneous transhepatic cholangiography and biliary drainage. Journal of Vascular and Interventional Radiology 200314 S243-S246.

27 Cesareo R, Palermo A, Pasqualini V, Cianni R, Gaspa GL, Manfrini S \& Pacella CM. Radiofrequency ablation for the management of thyroid nodules: a critical appraisal of the literature. Clinical Endocrinology 201787 639-648. (https://doi.org/10.1111/cen.13422)

28 Huh JY, Baek JH, Choi H, Kim JK \& Lee JH. Symptomatic benign thyroid nodules: efficacy of additional radiofrequency ablation treatment session-prospective randomized study. Radiology 2012263 909-916. (https://doi.org/10.1148/radiol.12111300)

29 Negro R, Salem TM \& Greco G. Laser ablation is more effective for spongiform than solid thyroid nodules. A 4-year retrospective follow-up study. International Journal of Hyperthermia 201632 822-828. (https://doi.org/10.1080/02656736.2016.1212279)

30 Pacella CM, Mauri G, Achille G, Barbaro D, Bizzarri G, De Feo P, Di Stasio E, Esposito R, Gambelunghe G, Misischi I et al. Outcomes and risk factors for complications of laser ablation for thyroid nodules: a multicenter study on 1531 patients. Journal of Clinical Endocrinology and Metabolism 2015100 3903-3910. (https://doi.org/10.1210/ jc.2015-1964)

31 Pacella CM, Mauri G, Cesareo R, Paqualini V, Cianni R, De Feo P, Gambelunghe G, Raggiunti B, Tina D, Deandrea M et al. A comparison of laser with radiofrequency ablation for the treatment of benign thyroid nodules: a propensity score matching analysis. International Journal of Hyperthermia 201712 1-9.

32 Cesareo R, Pasqualini V, Simeoni C, Sacchi M, Saralli E, Campagna G \& Cianni R. Prospective study of effectiveness of ultrasound-guided radiofrequency ablation versus control group in patients affected by benign thyroid nodules. Journal of Clinical Endocrinology and Metabolism 2015100 460-466. (https://doi. org/10.1210/jc.2014-2186)

33 Na DG, Lee JH, Jung SL, Kim JH, Sung JY, Shin JH, Kim EK, Lee JH, Kim DW, Park JS et al. Radiofrequency ablation of benign thyroid nodules and recurrent thyroid cancers: consensus statement and recommendations. Korean Journal of Radiology 201213 117-125. (https://doi.org/10.3348/kjr.2012.13.2.117)

34 Garberoglio R, Aliberti C, Appetecchia M, Attard M, Boccuzzi G, Boraso F, Borretta G, Caruso G, Deandrea M, Freddi M et al. Radiofrequency ablation for thyroid nodules: which indications? The first Italian opinion statement. Journal of Ultrasound $2015 \mathbf{1 8}$ 423-430. (https://doi.org/10.1007/s40477-015-0169-y)

35 Gharib H, Papini E, Garber JR, Duick DS, Harrell RM, Hegedüs L, Paschke R, Valcavi R, Vitti P \& AACE/ACE/AME Task Force on Thyroid Nodules. American College of Endocrinology, and Associazione Medici Endocrinologi Medical Guidelines for clinical practice for the diagnosis and management of thyroid nodules 2016 update. Endocrine Practice 22 622-639.

36 Jung SL, Baek JH, Lee JH, Shong YK, Sung JY, Kim KS, Lee D, Kim JH, Baek SM, Sim JS \& Na DG. Efficacy and safety of radiofrequency ablation for benign thyroid nodules: a prospective multicenter study. Korean Journal of Radiology 201819 1-7. (https://doi.org/10.3348/ kjr.2018.19.1.1)

Received 16 August 2018

Revised version received 19 October 2018

Accepted 5 November 2018 